SPECIAL ISSUE

\title{
Subjects, Topics, and Anchoring to the Context Roland Hinterhölzl
}

Abstract. The article discusses the connection between the syntactic and semantic properties of weak, strong, and referential DP subjects. In particular, I argue that nominal expressions possess a situation argument and that their interpretation and their distribution follow from the presuppositional requirements that the determiner imposes on the individual argument and situation argument of its complement nominal. These presuppositional requirements, I then argue, are embodied by local relations of the subject to a distinct head in the $\mathrm{C}$ domain, Fin $^{0}$ in the system of Rizzi 1997, where specific referential values of discourse antecedents are accessible.

\section{Introduction}

In this article, I argue that sentences need to be anchored to the context in one of two ways, either by an individual identified in the context or by a situation located in time and space in the context. I will address the role of subjects, tense, and finiteness in this anchoring process. In particular, I will discuss the interpretation of three types of nominal expressions serving as subjects, namely weak DPs, strong DPs, and anaphoric or referential DPs, and argue that their interpretation is tied to their syntactic licensing, which takes place in three different domains: while weak DPs are licensed in the $\mathrm{v}$ domain, strong DPs are licensed in the $\mathrm{T}$ domain and referential DPs in the $\mathrm{C}$ domain. In particular, I will argue that nominal expressions relate a situation and an individual.

The following subsection provides the background on the distinction between weak and strong determiners.

\subsection{The Definiteness Effect and the Distinction between Weak and Strong Determiners}

Milsark (1974) notes that some DPs are possible in there-insertion contexts while others are not, as is illustrated in (1a,b). He distinguishes between the two types of DPs with the terms weak and strong. Definite DPs, as is shown in (1c), behave like strong DPs in being excluded in the there-insertion environment, which is thus characterized as giving rise to the definiteness effect.

(1) a. There are some/three/many/few/no children in the garden.

Weak

b. *There is (are) every/each/all/most child(ren) in the garden. Strong

c. *There are the children in the garden.

Strong

Milsark also notes that weak DPs have a cardinal interpretation in definitenesseffect contexts, while they have a proportional reading (a strong-like interpretation)

I thank two anonymous reviewers for extensive and very helpful comments on an earlier draft of this article. All remaining errors are mine. 
outside these environments: few in (1a) means something like few in number, whereas in (2) it means something like a small percentage.

(2) Few children like vegetables. $(\neq$ There are few children that like vegetables.)

Furthermore, Milsark notes that the cardinal reading of weak determiners is excluded altogether with individual-level predicates, as in (2), but that stage-level predicates allow for both the cardinal reading and the proportional reading, as is illustrated in (3). Roughly speaking, stage-level predicates express temporary or accidental properties while individual-level predicates express (more or less) permanent or inherent properties. I will briefly discuss a formal account of this distinction in section 1.3 below.

(3) Few children are singing.

a. There are few children who are singing.

b. Few of a contextually given set of children are singing right now.

The data in (2) and (3) raise the question why the cardinal reading of weak DPs should be excluded with individual-level predicates. Milsark's reply to this is tentative: he proposes that only strong DPs make good topics and that being a topic is a prerequisite for individual-level predication. I will come back to this proposal and show that it is basically correct and argue that individual-level predicates can only be anchored via their individual argument (since their situation argument cannot be located in space), while stage-level predicates can be anchored via either their individual argument or their situation argument.

Milsark finally proposes that strong determiners are quantifiers while weak determiners are interpreted as predicates - they have an adjective-like interpretationwith their individual argument being bound by an existential operator that is introduced by there. As is pointed out by Herburger (1997), the problem with this account is that existential quantifiers are monotone-increasing operators, as is illustrated in (4), while not all weak determiners behave like such operators. On the contrary, few, no, and at most behave like monotone-decreasing operators, as is illustrated in (5).

(4) a. Some small children are playing. $\rightarrow$ Some children are playing.

b. ${ }^{*}$ (Few small children are playing. $\rightarrow$ Few children are playing.)

(5) a. All children are playing. $\rightarrow$ All small children are playing.

b. Few children are playing $\rightarrow$ Few small children are playing.

Herburger points out that a possible solution to this problem would be to decompose a decreasing quantifier into a wide-scope negation and an increasing quantifier: $f e w=$ not + many and no $=$ not + some. Some argument for this assumption will be given in section 5.3 below. Herburger herself follows a different route, the one proposed by Higginbotham (1987), and suggests that weak determiners like few are ambiguous 
between a proportional determiner that occurs in non-definiteness-effect environments and a symmetric determiner that occurs in definiteness-effect environments.

What remains to be explained is why there should be a correlation between the environment a DP occurs in and the interpretation that its determiner receives. Furthermore, the question arises why strong DPs involve quantification over a given set of individuals, as indicated in (3b), while weak DPs seem to introduce pieces of new information. The point of sentences like (1a) and (3a) seems to be to inform the hearer of the presence of a hitherto unidentified group of children. In other words, the question is why sentences containing weak subjects go hand in hand with thetic judgments while sentences containing strong subjects typically give rise to categorical judgments. I will discuss the tenets of the distinction between thetic and categorical judgments in detail in section 5.

In the next subsection, I provide the relevant background on the distinction between strong and weak definites.

\subsection{The Distinction between Weak and Strong Definites}

As we saw in the last subsection, definite DPs involve strong determiners, since they are excluded in definiteness-effect contexts. Yet there is evidence that they give rise to two different readings, which are generally referred to as their weak and strong readings.

Definite DPs in Germanic languages seem to obey two slightly different usage conditions. First, they are used in environments in which there is no discourse antecedent and they pick out an individual with a unique property, as is illustrated in (6). Second, they are used to pick out an individual that has been introduced in the previous context, as is illustrated in (7). Note that the uniqueness property seen in (6) is neither a sufficient nor a necessary condition for the anaphoric use of the definite determiner seen in (7), given that there may or may not be other men in the room.

(6) (Out of the blue:)

The sun is shining today.

(7) A man and a woman came into the room. The man wore a green hat.

There is evidence that these two uses of the definite article are based on a distinction in grammar. Several Germanic languages/dialects have long been known to have two full article paradigms (see Heinrichs 1954 for the Rhineland dialects, Scheutz 1988 and Schwager 2007 for Bavarian, and Ebert 1971 for the Frisian dialect of Fering). In Standard German the distinction becomes apparent in certain preposition-article combinations:

(8) a. Hans ging in-s Haus. $\mathrm{D}_{\text {weak }}$ John went into-DET.DEF house 'John went into the house.' 


\section{Roland Hinterhölzl}

b. Hans ging in das Haus.

$D_{\text {strong }}$

John went into the house

We can use the abbreviations $D_{\text {weak }}$ and $D_{\text {strong }}$ to refer to the two forms of the definite determiner (which, as established in section 1.1, is a strong determiner). As is illustrated in (9), adapted from Schwarz 2009, $D_{\text {weak }}$ in this context is subject to a uniqueness requirement, as expected (a government has only one chancellor but is composed of a number of ministers), while such a requirement is irrelevant for $\mathrm{D}_{\text {strong. }}$.

(9) a. In der Kabinettssitzung wird ein neuer Vorschlag vom in the cabinet.meeting is a new proposal by.DET.DEF Kanzler/??Minister erwartet. chancellor/minister expected 'In the cabinet meeting a new proposal by the chancellor/minister is expected.'

b. Hans hat gestern einen Minister interviewt. John has yesterday a minister interviewed In der Kabinettssitzung wird ein neuer Vorschlag von dem Minister in the cabinet.meeting is a new proposal by the minister erwartet.

expected

'John interviewed a minister yesterday. In the cabinet meeting a new proposal by the minister is expected.'

According to Schwarz 2012, the core meaning of the definite article involves the uniqueness property relativized to a situation. In Schwarz's account, the situation argument is introduced by the definite determiner. The interpretation of $D_{\text {weak }}$ is thus:

(10) $\llbracket D_{\text {weak }} \rrbracket=\lambda s \lambda P . x P(x)(s)$

The denotation of a weak definite DP is the unique individual that has the nominal property in the relevant situation. In other words $D_{\text {weak }}$ is a function that takes a situation argument and a nominal predicate and returns the unique individual that satisfies the nominal predicate in the relevant situation.

\subsection{Situations and the Essentials of Event Semantics}

Davidsonian event semantics has taken on a central role in linguistic theory. The central claim in Davidson 1967 is that the logical form of action sentences involves events, which are concrete particulars with a location in space and time.

According to the standard (pre-Davidsonian) view, a transitive verb, like read in the sentence in (11a), introduces a relation between two individuals, the subject John and the object the book, giving rise to the logical form in (11b). 
(11) a. John read the book.

b. READ(John, the book)

But Davidson points out that such a representation as (11b) does not allow us to refer explicitly to the action described by the sentence in (11a) and to modify it further by specifying, for instance, that John did it carefully, on the sofa, and at midnight. We may ask the question what it refers to in John read the book and he did it carefully. Davidson's answer is that action verbs introduce an additional event argument that stands for the action proper.

In other words - replacing the term event with the more general term situation - the logical form of the sentence in (11a) involves a three-place relation between two individuals and a situation. In this approach the logical form of (11a) is as specified in (12a) and amounts to the speaker's claim that there is a situation in which a particular individual named John read a contextually salient book in it.

(12) a. $\exists s$ READ(John, the book, $s)$

b. $\exists s \operatorname{past}(s) \& \operatorname{READ}(\mathrm{John}$, the book, $s)$

This enrichment of the underlying ontology has proven to be very fruitful for explaining a number of combinatorial and inferential properties of linguistic expressions, including adverbial modification, which I cannot go into in this article. One direct application of this approach that will become relevant in the course of the article is the treatment of tense and aspect. Tense can be treated as a predicate on the event argument of the verb that relates it to the utterance time, as is illustrated in (12b) and as will be refined in section 4 .

Another application of this enriched ontology that is of direct relevance for the purposes of our article is Kratzer's (1995) merger of event semantics with the distinction between stage-level and individual-level predicates. Crucially in her account, stage-level predicates possess an extra situation argument whereas individual-level predicates lack such a situation argument. The lexical entries for a typical stage-level predicate and a typical individual-level predicate in this approach are:

\section{(13) a. drunk: $\lambda x \lambda e \cdot \operatorname{DRUNK}(e, x)$ \\ b. intelligent: $\lambda x$. INTELLIGENT $(x)$}

However, I will not follow this account. Rather, as already pointed out above, I will pursue a neo-Davidsonian approach in which individual-level predicates too have a situation argument, but one that, following Chierchia (1995)—who distinguishes between location-dependent events and location-independent events - cannot be located in space. The background for this is the following. While Davidson's original proposal was that only verbs of a certain type, so-called action verbs, have an extra event argument, Higginbotham \& Ramchand (1997) propose that all predicatesincluding all the verb types in Vendler's (1957) terminology, that is, accomplishments, achievements, activities, and states, but also nouns and adjectives - have an event or situation argument. 


\section{Roland Hinterhölzl}

Proposing that nominals have a situation argument, the main research question of this article is how this situation argument is interpreted. I will argue that the presuppositional properties of the determiner decisively restrict the situation argument's interpretation.

\subsection{Outline of the Article}

The article is organized in the following way. I will start out by tackling the distinction between weak and strong definites, arguing that the interpretation of nominal expressions involves a situation argument. The account I provide in section 2 is based on the distinction between the referential and attributive uses of definite descriptions. In particular, I will show that the meaning of strong definites corresponds to the referential use of nominal expressions and the meaning of weak definites corresponds to their attributive use. This account will later be applied to the broader distinction between weak and strong determiners in section 5. In section 3, I will discuss what the referential-attributive distinction can tell us about the distinction between de dicto and de re readings of nominal expressions. In particular, I will argue that the distinction between the referential and attributive uses and the proposed account of it, which crucially employs a situation argument in nominals, can explain the different types of $d e$ re readings in intensional contexts. In section 4 , I will introduce the reference situation as an important element of temporal anchoring and discuss its interaction with tense in main and embedded clauses. Section 5 discusses the two ways of referentially anchoring the clause in the context: as a thetic judgment and as a categorical judgment. I will take up Ladusaw's (1994) account of Brentano's (1874) original distinction and argue that this account implies that weak DPs are licensed in the v domain while strong DPs must be licensed outside of the v domain. Finally, section 6 presents arguments from the German variety Cimbrian that referential DPs are licensed by entering into a local relation with FinP in the $\mathrm{C}$ domain. In particular, I will argue that clausal anchoring is achieved via FinP, by showing how the latter process interferes with wh-movement in a language in which the V2 constraint induces a bottleneck effect in FinP. Section 7 summarizes the article.

To outline the proposal briefly: A DP is referential if both its individual argument and its situation argument are given in the context. A DP has a strong interpretation if its situation argument is given in the context. A DP has a weak interpretation if neither its individual argument nor its situation argument is given in the context. Strong DPs can be licensed in the $\mathrm{T}$ domain, because tense makes available a reference situation that is anchored to the context via FinP. Weak DPs are licensed in that their situation argument is identified with the situation argument of the verb, while referential DPs need to enter into a licensing relation with FinP in the $\mathrm{C}$ domain, to get access to the value of the individual argument of their discourse antecedent.

\section{The Referential and Attributive Uses of Definite Descriptions}

It is well known that definite expressions like the president of the US and the king of France have different denotations depending on the time of their evaluation, as is 
illustrated in (14). For this reason the use of the subject the king of France yields a sentence that may be true in the context of evaluation in (15a) but yields a sentence that is inappropriate or false in the context of evaluation in (15b).

(14) a. In 1994, the president of the US was Bill Clinton.

b. In 2014, the president of the US was Barack Obama.

(15) a. In 1798, the king of France was bald.

b. ??In 2010, the king of France was bald.

Strawson (1950) held that a sentence like (15b) had no truth value, since the subject as a referential expression has a presupposition that there is an individual that answers to the description king of France, and this presupposition is not satisfied in (15b). However, Russell (1905) argued that (15b) was false, since the subject has to be analyzed as a predicate of an individual in the relevant context, one that is necessarily false as there presently is no (unique) king of France.

On closer inspection it turns out that both Strawson and Russell were right, as was pointed out by Donellan (1966), who spoke of the referential and attributive uses of a definite description.

(16) a. A man came in. The man wore a green hat.

b. A person was killed in a terrible way. The murderer must be insane.

c. We had a picnic in the park last weekend. John brought the beer.

In (16a), which illustrates the referential use, the expression the man simply picks up the referential value of its discourse antecedent, but in (16b), the expression the murderer is interpreted in a different way. Whereas in (16a) the speaker and the addressee, having heard the speaker's first sentence, can be taken to be familiar with the individual the speaker is reporting about, the speaker of (16b) is not familiar with the individual that committed the crime. Instead, the speaker may identify that individual $x$ by recourse to a property of $x$ in the given situation: $x$ is the murderer in the previous killing event. Similar considerations apply to the bridging relation in (16c): the beer is identified as a prototypical ingredient of the given picnic situation. Thus $(16 \mathrm{~b}, \mathrm{c})$ illustrate the attributive use of definite descriptions.

Interestingly, these interpretational differences correspond to syntactic differences: in German, while a referentially used DP is typically deaccented and scrambled to a high position in the middle field, an attributively used DP receives an accent and is licensed in a lower position in the middle field. This is illustrated in (17), which contrasts referential and attributive direct objects. The constituent receiving the main accent is indicated with italics. The direct object in (17a) is deaccented and preferably realized in a position above the frequency adverb, as shown. 
(17) a. Hans hat gestern Maria getroffen.

John has yesterday Mary met

Er hat seine Freundin sofort umarmt.

he has his girlfriend immediately embraced

'John met Mary yesterday. He immediately embraced his girlfriend.'

b. Hans will morgen ein Picknick machen.

John wants tomorrow a picnic make

Er hat sofort das Bier eingekühlt.

he has immediately the beer put.into.the.refrigerator

'John wants to have a picnic tomorrow. He immediately put the beer in the refrigerator.'

We may account for the interpretational variability of definite descriptions by assuming that the interpretative function is sensitive to world and time parameters. These are notated with superscripts in (18) and (19); $w_{0}$ denotes the actual world, while $w_{1}$ denotes a possible alternative world in which Hillary Clinton won the last election for US president.

(18) a. $\llbracket$ the president of the US $\rrbracket^{1994}=\{$ Bill Clinton $\}$

b. 【the president of the US $\rrbracket^{2004}=\{$ Barack Obama $\}$

(19) a. 【the president of the US $\rrbracket^{w_{0}}=\{$ Donald Trump $\}$

b. 【the president of the US $\rrbracket^{w_{1}}=\{$ Hillary Clinton $\}$

An alternative way of representing this interpretational variability is to say that nominal expressions have a situation argument, with situations understood as parts of worlds extending over a given time span (Kratzer 2007; see also Percus 2000, Hacquard 2010, Keshet 2008, and Schwarz 2012). For our approach, we also have to assume that situations (like most types of events) occupy a certain location in space. In this approach, the description president denotes a relation between an individual and a situation, which is located in a world, in time, and in space:

(20) [president of the US] $(x, s)$

We can then assume that a strong determiner (in contradistinction to a weak determiner) imposes the presupposition that the situation argument of the nominal expression is given in the context. This case corresponds to the attributive use of a definite description. As we will see in section 5, weak determiners lack such a presupposition, and the situation argument of weak DPs is identified with the situation argument of the verb. As far as referentially used definite descriptions are concerned, I propose that the presupposition that is imposed by the determiner in this case is even stronger: it not only requires that the situation with respect to which the nominal is evaluated is given in the context, it also requires that the individual referred to by the nominal is already given in the context. This distinction is shown in (21). The presuppositions are indicated by the formulas 
$\exists s s \in C, \exists a a \in C$, and $P(s)=a$, with $a$ being the concrete individual introduced in the previous discourse.

(21) a. $\llbracket \mathrm{D}_{\text {weak }} \rrbracket=\lambda P: \exists s s \in C \& \mathrm{w} x P(s)=x \cdot x$

b. $\llbracket \mathrm{D}_{\text {strong }} \rrbracket=\lambda P: \exists s s \in C \& \exists a a \in C \& P(s)=a \cdot a$

Attributive use

Referential use

In other words, a referentially used DP does not establish a separate (discourse-) new referent; it simply picks up the referent of its antecedent, which it presupposes. Its grammatical features and its nominal description are used as presuppositions, meaning they only serve to discriminate the relevant antecedent in the discourse. In other words, a referentially used DP behaves in all respects like a (referential) pronoun.

At this point a note on my use of the term presupposition is in order. It is generally assumed that in the referential use of a definite description, say, the man, it is only presupposed by the speaker that the actual discourse antecedent is a man; it is not predicated (or asserted) by the speaker. This is a classical presupposition, in the pragmatic sense of the term. I use the term here in a grammatical sense. The definite determiner is a function that takes a nominal predicate with an individual argument and a situation argument and maps it onto the respective individual of whom it is true in the relevant situation. The grammatical presupposition of an attributively used definite determiner requires that the relevant situation argument be given, otherwise this function is undefined. The grammatical presupposition of a referentially used definite determiner is such that the function is undefined unless the values of both the situation argument and the individual argument of the nominal predicate are given. (The attributive-referential distinction can be applied to all strong determiners, in the sense of Milsark 1974, as we will see in section 5.) I will henceforth use the term grammatical presupposition, since I assume that these values not only need to be given in the context but also in the syntactic structure. As I will argue in more detail in section 6, a presuppositional DP must enter into a local (Agree) relation with a specific syntactic head, where these values are assigned. In the next section, I will argue that the distinction between the attributive and referential uses of a nominal expression is also useful in accounting for the diverse readings that nominal expressions obtain in intensional contexts.

\section{On the Distinction between De Dicto and De Re}

It is well known that an intensional operator can affect the interpretation of noun phrases, including definite descriptions. The sentence in (22) may be used to report John's desire to meet the author of Waverley, whoever he might be, constituting the so-called de dicto reading, or (22) may be used by a speaker who knows about John's desire to meet Walter Scott to report this propositional attitude, representing the socalled de re reading.

(22) John wants to meet the author of Waverley. 


\section{Roland Hinterhölzl}

One way to account for this ambiguity is to assume that these two interpretations result from different scope relations of the definite description with respect to the intensional operator, where the de re reading is taken to follow from a wide-scope interpretation with respect to the verb and the de dicto reading is taken to follow from a narrow-scope interpretation:

(23) a. The author of Waverley, namely Walter Scott, is such that John wants to meet him.

b. John has the desire to meet the author of Waverley (whoever it might be).

However, there are problems with the scopal account of the distinction between de dicto and de re. As May (1977) pointed out, a quantificational noun phrase embedded in a tensed clause cannot take scope out of it; yet such a noun phrase can have a de re interpretation, as is illustrated in (24), taken from Keshet \& Schwarz 2014. The sentence in (24a) is only coherent on a de re interpretation of everyone in this room, which means, on the scopal account, that it must take scope over the intensional verb, as in the paraphrase in (24b); this requires extraction of a quantified noun phrase out of a tensed clause.

(24) a. Mary thinks that everyone in this room is outside.

b. Everyone in this room is such that Mary thinks that he/she is outside.

One could relax the conditions of extraction for these specific cases, but as Keshet \& Schwarz (2014) point out, this will not do, since there is actually evidence that the quantifier of an expression interpreted de re can or must be interpreted with narrow scope with respect to the intensional operator:

(25) If everyone in this room were outside of the room, it would be empty.

(Keshet 2008:12)

Note first that conditional clauses are generally considered to be islands for extraction; nevertheless the noun phrase everyone in this room needs to have a de re interpretation for the sentence to be noncontradictory. Interpreting the quantified subject outside of the conditional clause would yield the interpretation that for each person who is in this room in the actual world, say $a, b$, and $c$, it holds that if that person were outside of the room, it would be empty; however, the room would only be empty if all three of them were outside of the room in the same hypothetical scenario. This requires that the quantified subject is (able to be) interpreted in the conditional clause.

One way to solve this problem is to assume syntactically represented variables for worlds and times. In particular, Percus (2000), Keshet (2008), Hacquard (2010), Schwarz (2012), and Elbourne (2013) have put to use so-called possible-world pronouns to account for de re readings with narrow quantificational scope. In our approach, we could say that the de re reading results from an in situ interpretation of a definite description that is used referentially, while the de dicto reading results from 
an in situ interpretation of the definite description that is used attributively, where the presupposed given situation is identified with the alternative situation $s_{i}$ (in $w_{1}$ ) introduced by the intensional operator. I will argue in section 4 that this alternative situation is syntactically represented, since the embedded Tense head (by introducing a reference situation) is interpreted as expressing a temporal relation between it and the matrix event (cf. Hacquard 2010 for the claim that the situation pronoun is introduced by Aspect).

In this respect, it is interesting to note that, as Fodor (1970) pointed out, noun phrases can give rise to more than the two readings that are expected under the scopal account of the distinction between de dicto and de re; this is discussed in detail by Keshet \& Schwarz (2014). The background is a scenario in which a contestant gets to choose the professionals they have to face in a game show. Our contestant Mary can choose her next opponent based on headshots of various professionals. Mary has narrowed down her choice to John or Sue (but has not decided yet which one of them), both of whom the speaker (but not Mary) knows to be plumbers. In this scenario, the speaker can report Mary's attitude with the following sentence.

(26) Mary wants to face a plumber next.

Note that in this scenario neither the de re interpretation nor the de dicto interpretation of the indefinite noun phrase is correct. The de dicto interpretation is incorrect since Mary cannot be described as having the desire to face anyone who is a plumber. She wants to face either John or Sue and is ignorant about their professional status. The de re interpretation is also incorrect since Mary does not have a propositional attitude towards a specific individual. In the given scenario it is not true that she has decided to face John nor is it true that she has decided to face Sue.

In our approach, the correct reading can be identified with an in situ interpretation of an attributively used indefinite description where the presupposed given situation is identified with the utterance situation or with the situation of looking at the headshots, which is part of the actual world. This reading differs from the standard de re reading, which would be obtained by the referential use of the indefinite description but is not warranted in the given scenario, since the speaker does not know which opponent Mary has decided to face.

In the next section, I will discuss the role of tense in the anchoring process and thereby introduce the reference situation that-as we have just seen-plays a major role in licensing the attributive use of definite DPs and strong determiners in general.

\section{Anchoring the Predicate in the Context: The Role of a Reference Situation}

It is generally assumed that the clause is anchored by tense (and mood) to the context. Tense in this conception has the role of temporally situating the event expressed by the verb with respect to the utterance situation. For instance, in event semantics, the interpretation of (27a) can be specified as in (27b), that is, the sentence represents the claim of the speaker that there is an event of visiting in the past (at a time before 


\section{Roland Hinterhölzl}

the utterance situation) in which a certain individual named John figures as the agent and this individual's mother figures as the theme.

(27) a. John visited his mother.

b. $\exists e \operatorname{visiting}(e) \& \operatorname{past}(e) \& \operatorname{agent}(e, \operatorname{John}) \&$ theme $(e$, his mother $)$

(28) a. John visited his mother. $e_{1}$

b. She was sick. $\quad e_{2}$

c. $e_{1}<e_{2}<s, e_{2}<e_{1}<s, e_{1} \mathrm{O} e_{2}<s$

d. She was sick one week before/later.

As is illustrated in (28), this simple linking approach turns out to be insufficient, when one considers sentences embedded in a discourse. For instance, linking the sickness event of John's mother in (28b) directly to the utterance event would be compatible with the temporal readings specified in (28c): $e_{1}$ could precede or follow or overlap with $e_{2}$ as long as both of them precede $s$ (the speech event). However, (28b) is naturally read as indicating that John's mother was sick during the time of his visit. This can be achieved via the introduction of a reference situation. According to Reichenbach (1947), tense establishes a link between speech time $(s)$ and reference time $(r)$, as is illustrated in (29a). The event expressed by the verb $(e)$ is then situated with respect to $r$ via aspect, as is illustrated in (29b).

(29) a. The meaning of tense according to Reichenbach

Past $:=r<s$

Present : $=r \subseteq s$

b. The meaning of aspect according to Reichenbach

Perfect $:=e<r$

Imperfect $:=e \subset r$

In the discourse in (28), we can assume that $r$ for (28b) is identified with a discourse antecedent that has been established in the previous context, namely the event of John's visit (28a), and it is this event with respect to which the predicate is (temporally) situated in (28b) and to which the temporal adverbial in (28d) refers, meaning that John's mother was sick one week before or after his visit.

For reasons that will become clear in section 6, I assume that this reference situation is introduced in FinP in the $\mathrm{C}$ domain and is taken up by Tense. Note in particular that the temporal predicate past has a referential use in (28b). It does not establish a new reference situation in relation to the given utterance situation; it acts as a function that only presupposes that a past temporal relation is present in the context and takes the latter's value as its output.

In clauses embedded under an attitude predicate, Tense can have the same two functions: attributive or referential. Embedded Tense only differs from main-clause Tense in that it either establishes a reference situation (possibly in an alternative world) that is temporally situated with respect to the matrix event, as is illustrated in (30), or it presupposes the presence of a matrix tense predicate, whose reference- 
situation value it picks up. The latter is typical or the only option for Tense in subjunctive embedded clauses (cf. Giorgi \& Pianesi 1997).

(30) John believed that Peter won the race.

Past tense in the embedded clause in (30) locates the reference situation of the winning event in the past with respect to the matrix believing event. Since I am only concerned with main clauses in this article, I will leave further issues with the anchoring of embedded clauses aside.

In the next section, I will take up the question how the situation argument of nominals that we introduced in sections $1-3$ is interpreted in the clause. We will see that the presence/absence of a determiner and its presuppositional properties distinguish between weak, strong, and referential DPs. Furthermore, I will argue that these presuppositional properties determine the syntactic distribution of nominal expressions, and I will discuss the role of strong and weak subjects in giving rise to categorical and thetic judgments.

\section{Weak and Strong Determiners in Categorical and Thetic Judgments}

Let's take a step back at this point to see what is actually new in the proposal. First note that the assumption of a reference event or topical situation is not new at all. For instance, Elbourne (2013) proposes that the content of the speech act of assertion is analyzed as an Austinian proposition, that is, a pair consisting of a topic situation, about which the speaker intends to say something, and a proposition that is a set of situations: if the topic situation is a member of the set, the speaker has spoken truly (cf. Austin 1961, Barwise \& Perry 1983:160, Kratzer 2004, 2006). For example:

(31) a. Mary greets John.

b. $\lambda s$. Mary greets John in $s \&$ Mary $=f(s) \&$ John $=g(s)$

Note that in this representation nominals and the verb are evaluated with respect to the same event/reference situation. However, it appears that there are at least two general situations in which a nominal must be evaluated with respect to an event different from that of the verb that takes it as an argument: relativized DPs, as illustrated in (32), and DPs with a strong or categorical interpretation.

(32) a. John read the book that Mary recommended.

b. In $s_{2}$ John read the unique book $x$ in $s_{1}$ such that Mary recommended $x$ in $s_{1}$.

In (32), the book in the matrix clause must be evaluated with respect to the situation characterized by the embedded clause: $x$ must be the unique book in the recommendation situation and not necessarily in the reading situation (John's reading could be situated in a library containing thousands of books). 


\section{Roland Hinterhölzl}

As is illustrated in (33) for German, weak and strong DP subjects have a different distribution in the clause. When the DP has a weak interpretation, with the quantifier exhibiting a cardinal reading, the DP subject is licensed in a lower, verb-adjacent position. When the DP has a strong reading, in which the quantifier has a proportional interpretation, the DP subject occurs in a higher position.

(33) a. weil hier viele Frauen arbeiten since here many women work 'since (there are) many women (who) work here'

b. weil viele Frauen hier arbeiten since many women here work 'since many (of the) women work here'

Weak, existential, cardinal reading

Strong, proportional, presuppositional reading

We can take these facts to indicate that weak DPs are licensed by being evaluated with respect to a new situation that is identified with the event denoted by the verb, while strong DPs (as already indicated above) are evaluated with respect to a given reference situation that is introduced by Tense.

In the present account we can say that strong determiners select for a situation argument that is given in the context at the point of the utterance $\left(s \in S_{\mathrm{c}}\right)$. Since such a new situation is introduced by Tense, we submit that a strong DP is licensed in the T domain, while a weak DP is licensed in the v domain. In the following subsection, we will develop this approach a bit further by looking at the differences between categorical and thetic sentences.

\subsection{On the Difference between Categorical and Thetic Judgments}

As we briefly discussed in section 1, Milsark (1974) proposed a two-way distinction between DPs, a two-way classification of one-place predicates, and a generalization about how these elements can be combined. As is illustrated in (34), a strong subject can be combined both with a stage-level predicate and with an individual-level predicate, while a weak subject ( $\mathrm{sm}$ stands for the unstressed weak quantifier some) is only compatible with a stage-level predicate.

(34) a. The man is drunk.

b. The man is intelligent.

c. Sm men are drunk.

d. $*$ Sm men are intelligent.
Strong + stage level Strong + individual level

Weak + stage level

Weak + individual level

Diesing (1992) takes up Milsark's generalization and tries to derive it with a number of assumptions about the interface between syntax and semantics. Following Kratzer (1989), she assumes that weak readings of indefinites are the result of existential closure of a free variable, while strong readings involve quantificational operators. The domain of existential closure is the VP (the vP in present terminology), which contains the base position of subjects. 
Observing that raising predicates, as in (35a), allow reconstruction but control predicates, as in (35b), do not, Diesing proposes that the Infl head of individual-level predicates is transitive, while stage-level predicates may also combine with an unaccusative Infl. It therefore follows that subjects of individual-level predicates cannot reconstruct and thus cannot obtain a weak interpretation. This is illustrated in (36). I think the argument goes through but is based on a mere stipulation about Infl types.

(35) a. A man seems $t$ to be sick.

b. A man promised PRO to help us out.

(36) a. Some man is $t$ drunk.

b. Some man is PRO intelligent.

Ladusaw (1994) argues that Milsark's generalization can be derived from Brentano's (1874) distinction between thetic and categorical judgments. According to Brentano a thetic judgment consists in the presentation of an object, an entity or eventuality, and constitutes a simple judgment. A categorical judgment, by contrast, constitutes a double judgment, since it consists in the act of recognizing the object that is made to be the subject and the act of affirming or denying what is expressed by the predicate about this subject. As Ladusaw (1994:3) points out, the importance of this distinction consists in the fact "that one judgment form involves a presupposed subject in the sense that a precondition for making the judgment is that the mind of the judger must be directed first to an individual before the predicate can be connected to it."

Ladusaw explicitly makes reference to work by Kuroda (1972), who was the first to apply Brentano's distinction to a core distinction in Japanese grammar. In the thetic judgment in (37a), the subject is marked with the nominative particle $g a$, while in the categorical judgment in (37b), the subject is marked with the topic particle wa.

(37) a. Neko ga asoko de nemutte iru.

Thetic cat $G A$ there sleeping is

'The cat is sleeping there.'

b. Neko wa asoko de nemutte iru. cat $W A$ there sleeping is

Categorical

Ladusaw then proposes that what Brentano called presentations should be equated with (nominal) descriptions and that predication should be treated as a relation between an object and a property (basic in the case of individual-level predicates or derived from a description). Since a description-for instance, a cat sleeping in the garden in the thetic judgment in (38a) - is itself a composition of an eventuality description with various individual descriptions, Ladusaw (1994:5) argues that the theory of argument saturation must be taken to work on two levels, either by restricting a parameter in an eventuality description with another description or by specifying an object as the value of the parameter. 


\section{Roland Hinterhölzl}

(38) a. There was a cat sleeping in the garden.

Thetic

b. The cat was sleeping in the garden.

Categorical

The first option for argument saturation of course consists in functional application that involves an individual and a (derived) property. In the present account, this operation can only occur outside of the $\mathrm{vP}$ and involves $\lambda$ abstraction over the subject argument and a referential use of the subject DP, as is illustrated in (39). Assuming that the value of the definite description the cat in a contextually given situation (as presupposed by the referentially used determiner) is the individual $a$, predication in this case indeed involves a relation between an individual and a property.

(39) $[\lambda x . \exists e \operatorname{agent}(x, e) \&$ sleeping $(e) \&[$ in the $\operatorname{garden}](e)]\left(\mathbb{[}[\right.$ the cat $\left.]\left(x, s_{1}\right) \rrbracket=a\right)$

The second option consists in predicate modification where both the individual argument and the situation argument of the verb and of the subject are identified. Our case only differs from standard cases of predicate modification in that there is an additional restriction to the final step that comes from the meaning of the nominal description. I assume that the so-called indefinite determiner $a$ in its weak or nonspecific use ${ }^{1}$ occupies a Number head specifying the condition that there is one individual (at least one assignment) for which the nominal description cat is true in a given event, hence the final abstraction over this argument does not involve the $\lambda$ operator but can and must be strengthened to the existential operator:

(40) $\lambda e . \exists x \operatorname{cat}(x, e) \& \operatorname{agent}(x, e) \& \operatorname{sleeping}(e) \&$ [in the $\operatorname{garden}](e)$

The analysis of $(38 \mathrm{a}, \mathrm{b})$ can be considered correct insofar as it has the indefinite subject in a presentational thetic judgment being individuated for the first time in the newly presented event while it has the subject of a categorical sentence already having been individuated with respect to a situation previously introduced in the discourse.

The question that remains to be answered now is how a thetic judgment is anchored in the context. The answer is that the adverbial there in a presentational sentence is not an expletive but serves to locate in space the referential situation that the thetic judgment is about. The basic assumption is that thetic judgments characterize a situation and thus need to be anchored via the reference situation (a situation topic), while categorical judgments characterize an individual (or a set of individuals) and thus need to be anchored via this individual (an individual topic). There locates the reference situation either with respect to the utterance situation, as in (38a), or with respect to a situation established in the context, as in (41).

\footnotetext{
${ }^{1}$ In its specific use, I suggest, the indefinite article is a real determiner and occupies the D position, specifying the presupposition that the individual argument of the nominal predicate is known or familiar to the speaker but not to the hearer.

(C) 2019 John Wiley \& Sons Ltd
} 
(41) a. John visited his mother. There was a child crying in the garden.

b. I went to the local bar last night. Into the room walked a man with a green hat.

In (41a), the situation of a child crying in the garden is linked via there to the location of John's visit, and in (41b), the situation of a certain man appearing in the scene is linked via the preposed locative phrase into the room to the location of the speaker's visit to a local bar. Let us see in the next subsection how this account squares with standard accounts of there constructions.

\subsection{There as an Expletive and Alternative Theories}

In the literature we find two types of approaches (cf. Kallulli 2008, Hartmann 2008): there-insertion approaches (Stowell 1978, Chomsky 1981, 1995, 2000, 2001, Safir 1982, Bošković 1997, Sabel 2000) and approaches in which there is part of the predication (Jenkins 1975, Williams 1994, Moro 1997, Hoekstra \& Mulder 1990, É. Kiss 1996, Ramchand 1997, Felser \& Rupp 2001, Hazout 2004).

For the proponents of the first account, there is an expletive devoid of meaning and its sole function is to fill the subject position. Furthermore, they assume that there is a derivational relation between the sentences in (42), leading to a problem when confronted with the data in (43).

(42) a. There is a man in the garden.

b. A man is in the garden.

(43) a. A man seems to be in the room.

b. There seems to be a man in the room.

c. *There seems a man to be in the room.

The sentence in (43c) cannot be ruled out without further stipulations like Procrastinate (see Chomsky 1995), Merge-over-Move (see Chomsky 2000), or language-particular transformations as Th/Ex (see Chomsky 2001). Furthermore, as has been pointed out already by Milsark (1974), the there-insertion theory predicts readings that are not there. While the subject in (44b) is ambiguous between a strong and a weak reading, only a weak interpretation is available for the subject in (44a), in contrast to what is expected under the account involving there replacement at LF.

(44) a. There weren't many people in the room.

b. Many people weren't in the room.

(Milsark 1974)

The proponents of the alternative, predicational account assume that there has sufficient content to participate in a predication relation (as an argument or as a predicate). In this article, I cannot go into the differences between the diverse alternative accounts and will simply adopt that of Kallulli (2008), which in section 6.2 I will slightly extend for the purposes of anchoring. As is illustrated in 


\section{Roland Hinterhölzl}

(45), Kallulli proposes that there is base generated as the subject of a small clause in the complement domain of be and then raised into Spec,TP in the course of the derivation.

(45) a. There are many problems.

b. [тт there [Vp be $\left[\mathrm{PrP}_{\mathrm{PP}}\right.$ there $\left[\mathrm{Pr}^{\prime}\right.$ many problems]]]]

I will argue in section 6 that there must also enter into a licensing relation with FinP.

In the next subsection, I will present a further argument, besides the one from German (see (33)), that strong and weak subjects are interpreted in different syntactic positions. In English the two positions become evident when we consider the interaction of strong and weak DPs with respect to negation.

\subsection{The Syntax of Weak and Strong DPs in the Present Account}

Let us first return to Milsark's (1974) observations and see how they can be explained in the present account. The example in (34d), that is, the combination of a weak subject with an individual-level predicate, is excluded since the sentence can neither be anchored with respect to a contextually given individual/group of individuals, given that the weak subject serves to introduce a new one, nor via a situation argument, since the situation argument of an individual-level predicate by definition cannot be localized in space. In addition, there arises the question of whether the weak subject can be licensed via predicate modification with the verb, which in our account involves identifying the situation arguments of subject and predicate with each other. Potentially, the two situation arguments are incompatible, given that the event argument of the verb is not localizable in space while nominals are, as is indicated by expressions like the man (over) there and the opposition between different types of demonstrative elements, like this and that in English, which make salient a specific space that the individual argument of the nominal predicate occupies with respect to the speaker. In conclusion, (34d) is excluded either by failure of anchoring or by failure of semantic composition or both.

The question now arises of how the combination of a weak subject with a stagelevel predicate (34c) can be derived in the present account. Since indefinite nonspecific subjects are unable to anchor the predicate to the context according to our assumptions, the sentence must be anchored with respect to the situation argument of the verb, in time and space. While temporal anchoring is unproblematic and is achieved via Tense's reference situation (as explicated in section 4 above), the situation argument of the verb must also be located in space.

I suggest that this is achieved via the presence of a silent locative element in the structure. In the positive sentence in (46a), the strong and weak readings of the nominal expression some men seem to be able to arise in the same syntactic position. But the negative clauses in $(46 \mathrm{~b}, \mathrm{c})$ show that while a strong subject can occur in Spec, TP, a weak subject in this position is excluded. 
(46) It was a rather good situation...

a. (Only) some men were sick.

b. since some men were not sick (and we could rely on them).

c. *since sm men were not sick.

The only option for characterizing the situation in (46) is to use an existential there construction, as in (47a), or a negative quantifier in subject position, as in (47b). However, (47b) is ambiguous between a strong reading of the subject and a weak reading.

(47) a. There were no sick men (*and we could rely on them).

b. No men were sick $(\mathscr{L} / *$ and we could rely on them).

Note in particular that, in both (46) and (47), the strong reading licenses the continuation and we could rely on them, while the weak reading fails to do so.

I suggest that the strong and weak readings correspond to two different syntactic positions for the subject. Furthermore, I propose to derive the weak quantifier no as a combination of sentential negation and the weak quantifier $s m$ :

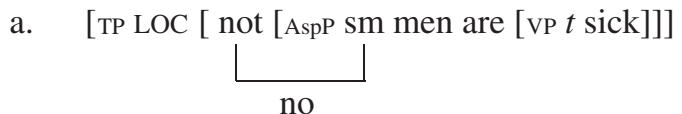

b. [TP no men are (not) [AspP [VP $t$ sick $]]]$
Weak reading

Strong reading

While the strong quantified DP no men is interpreted in Spec,TP, the weak quantifier is interpreted in Spec,AspP below sentential negation, with Spec,TP being filled with an empty locative element. ${ }^{2}$ It is quite possible that these two syntactic positions for the indefinite expression some, along with the distinct licensing conditions, correlate with a difference in internal structure: perhaps some in its strong interpretation occupies the D position and the weak sm occupies a lower position in the DP, as Déprez (2000) has proposed for different types of $n$ words exhibiting different types of licensing conditions. If this is correct, we could assume that weak sm occupies the Num(ber) position, parallel to the distinct structural analysis of the specific and nonspecific uses of the indefinite article $a$ proposed in section 5.1. For reasons of space I cannot go into further details motivating this analysis.

The syntactic analysis in (48) recalls the German data introduced in (33) above, showing that weak and strong DPs have a different distribution with respect to a specific class of adverbs. Interestingly, in Dutch, as in German, a weak subject is realized in a lower position, but unlike in both German and English, the subject

\footnotetext{
${ }^{2}$ An anonymous reviewer asks the interesting question whether the predicate can also be anchored by an adjunct or by an object. Note that in the present account a predicate could in principle also be situationally anchored by an adjunct, but then the predicate and its subject must overlap in their location, as I will argue below. I will have to leave open the question whether a categorical judgment can also be anchored via an object. 


\section{Roland Hinterhölzl}

position, Spec,TP, is occupied by the weak form er of the R pronoun daar 'there', which has a deictic locative interpretation and directly indicates that weak subjects cannot be licensed in Spec,TP:

(49) a. omdat er hier veel mannen werken

Weak reading because LOC here many men work 'because many men work here'

b. omdat veel mannen hier werken because many men here work

Strong reading

So there is important crosslinguistic evidence for the analysis proposed in (48). Let us now address the question of whether thetic judgments can also be based on strong subjects. The example in (47b) seems to indicate that this is possible. A more convincing example is the following case taken from Schwarz 2012.

(50) A: What was the political situation in Congress in 2004?

B: Most senators were Republicans.

The subject in (50B) is a strong DP, yet the sentence seems to characterize the political situation rather than a specific group of senators. We have a case in which an attributively used DP is evaluated with respect to a given situation, hence the strong reading. In this case, the subject is interpreted in Spec,TP, where its situation argument is identified with Tense's reference situation. Since the latter is individuated in the context, the answer can be taken to characterize a situation topic and thus constitutes a thetic judgment (the speaker may not have specific senators in mind but may simply be informed of the fact that the Republicans had the majority in the Senate that year).

I will have to leave this issue for further research. But our observations about the data in (46)-(50) seem to show that the element that occupies Spec,TP and the predicate in a thetic judgment must agree in their location in space, that is to say, they must be explicitly located in space with respect to the same given situation (either via a locative element or via a strong DP, which by definition has a given situation argument). It is in this sense that the locative expressions in Spec,TP in (41) can be called subjects.

Note that in contrast to this, in categorical judgments, which are anchored via an individual, the location with respect to which the subject is identified and the location with respect to which the verb is anchored often overlap but do not necessarily need to be identical.

Let us now briefly discuss how the present account compares with the standard account. Recall that the standard treatment of the interpretation of indefinites and weak quantifiers follows from Diesing's (1992) mapping hypothesis. As we briefly discussed above, the interpretation and distribution of indefinites and weak quantifiers in her account follows from two assumptions: (a) indefinites and weak quantifiers introduce free variables that need to be bound by an existential operator, and (b) existential closure applies to the $\mathrm{vP}$. 
Note that this account does not explain why subjects containing strong determiners have to move out of the vP. There is a lot of literature indicating that strong determiners and quantifiers are topics in the sense that the set of individuals they quantify over must be given in the context (cf. Hinterwimmer \& Endriss 2006). I conclude that the present account is thus preferable to Diesing's original account, since it also encompasses Ladusaw's (1994) insight into the distinction between categorical and thetic judgments.

In the next section, we will take a closer look at the syntactic details of the anchoring mechanism and at the role that locative elements and clitics have in this licensing process, through examination of the distribution of subjects in Cimbrian.

\section{Subjects in Cimbrian: A Case Study}

In this final section, I will provide some empirical support for the notion of grammatical presupposition introduced above. I will argue that contextual anchoring is only achieved if the anchoring expression (a strong or referential DP or its correlate) is moved into a specific position in the clause. I will argue that this position is FinP, in the $\mathrm{C}$ domain. The background of this proposal is the assumption that the semantic interpretation of DPs does not involve assignment functions in the semantics, which would allow for the interpretability of any DP in any syntactic position, but is syntactically determined in that there is a specific head in the $\mathrm{C}$ domain in which the values of discourse antecedents are assigned (see Hinterhölzl 2019 for further arguments coming from cases of possible and impossible coreference).

The data in this section is taken from joint work with Federica Cognola (see Cognola \& Hinterhölzl to appear for further details). Let us take a look at the distribution of subjects in Cimbrian, a German dialect spoken in the village of Luserna, Trentino, Italy.

(51) a. Bas hatt $=\mathbf{a r}_{j}$ herta gekoaft dar Luca $_{j}$ ? what has=he always bought the Luca 'What has Luca always bought?'

b. Bas hat=ta herta gekoaft dar Luca? what has $=D A$ always bought the Luca

c. *Bas hat herta gekoaft dar Luca? what has always bought the Luca

(52) a. *Dar Luca $_{j}$ hatt=ar ${ }_{j}$ herta gekhoaft in libar. the Luca has=he always bought a book 'Luca has always bought a book.'

b. *Dar Luca hat=ta herta gekhoaft in libar. the Luca has $=D A$ always bought a book

c. Dar Luca hat herta gekhoaft in libar. the Luca has always bought a book 


\section{Roland Hinterhölzl}

The distribution of subjects and subject-related clitics seen in (51) and (52) has given rise to the following generalization in the literature. $D a$ and subject clitics are ruled out in all cases in which the subject precedes the finite verb, but $d a$ or a subject clitic is obligatory in all cases in which the subject follows the finite verb (see Bidese \& Tomaselli 2005, Kolmer 2005, Bidese, Padovan \& Tomaselli 2012, Grewendorf \& Poletto 2015, Bidese \& Tomaselli 2018).

The crucial observation here is that subjects can follow the nonfinite verb when they are doubled by $d a$ or by a subject clitic pronoun. If doubled by $d a$, they are typically focused (new information or contrastive focus). In (53a) the subject constitutes new information in the discourse. If doubled by a pronoun, on the other hand, the subject constitutes a topic and is already given in the discourse, as in (53b).

(53) a. Haüt iz=ta khent dar nono.

today is $=D A$ arrived the grandfather

'The grandfather arrived today.'

b. Haüt $\mathrm{izz}=\mathrm{ar}_{j}$ khent $\left(\mathrm{dar}\right.$ nono $\left._{j}\right)$.

today is $=$ he arrived the grandfather

c. *Haüt iz khent dar nono.

today is arrived the grandfather

Note also that $d a$ but not subject clitics must co-occur with an overt NP subject. As is illustrated in (54), one element must realize the postverbal position. In other words, pro drop is ruled out in Cimbrian.

(54) a. *Haüt izz=ta khent.

today is $=D A$ arrived

b. Haüt izz=ar gånt ka schual.

today is $=$ he gone to school

'He went to school today.'

c. *Haüt izz=pro gånt ka schual.

today is gone to school

This observation has been taken to argue that $d a$ is a kind of subject expletive. In particular, it has been claimed that expletive $d a$ is distinct from the homophonous locative $d a$ 'here' (see Kolmer 2005, Grewendorf \& Poletto 2015:402, Bidese \& Tomaselli 2018), since the two can co-occur:

(55) Bas hat=ta gatont a khin da?

what has $=D A$ done a boy there

'What has a boy done there?'

(Grewendorf \& Poletto 2015:402)

Note also that $d a$ behaves differently from the English expletive there since it is compatible with definite as well as indefinite DPs, as we have already seen in (51) and (52). $D a$ seems to be a clitic element since nothing can intervene between it and the finite verb in main clauses and between it and the complementizer in embedded clauses.

(C) 2019 John Wiley \& Sons Ltd 


\subsection{Two Accounts of the Distribution of Subjects and the Role of Da in Cimbrian}

There is general agreement about the position of $d a$ in the clause. $D a$ is taken to be hosted in the lower portion of CP, that is, FinP (see Benincà 1988, 2006, Rizzi 1997), and it is generally assumed that its position with respect to the finite verb is due to Vto-C movement (see Bidese \& Tomaselli 2005, Bidese, Padovan \& Tomaselli 2012, Grewendorf \& Poletto 2015, Bidese \& Tomaselli 2018 for an analysis of Cimbrian as a V2 language).

As far as the function of $d a$ is concerned there are two different positions in the literature. Bidese, Padovan \& Tomaselli (2012) and Bidese \& Tomaselli (2018:15) propose a formal syntactic account in which $d a$ and subject clitic pronouns realize subject $\phi$ features in C (see Holmberg \& Platzack 1995 for the idea that in V2 languages $\mathrm{T}$ features are features of $\mathrm{C}$ ). In particular, they argue that the distribution of $d a$ and clitics is to be connected with the realization of the syntactic subject and of subject agreement (see also Kolmer 2005 for a similar analysis):

Both $\mathrm{T}$ and the lower $\mathrm{CP}$ layer, i.e. $\mathrm{FIN}^{0}$, are characterized by the EPP feature. The EPP feature in FIN $^{0}$ is $\phi$-independent as in German. As a matter of fact, it is probed by: a) the nominal subject raised to SPECFINP; b) direct merge of the $\mathrm{CP}$ expletive ' $z$; c) any $\mathrm{XP}$ raised/merged in the higher CP-layers. The EPP feature in $\mathrm{T}$ is always controlled from above, either by the nominal subject in SPECFINP or by a clitic subject in complementary distribution with expletive $-d a /$-ta.

(Bidese \& Tomaselli 2018:15)

On the other hand, Grewendorf \& Poletto (2015), studying the distribution of $d a$ in relative clauses, argue for a semantic account and propose that $d a$ is a Ground marker in CP. In particular, they argue that GroundP is a projection marking the ground context with respect to which the head noun individuated by the relative clause is interpreted. They propose that GroundP also hosts weak pronouns (in the sense of Cardinaletti \& Starke 1999) and that this is why $d a$ is in complementary distribution with them. Most importantly, they suggest that GroundP is a functional projection specified for old information (413). This is why $d a$ is obligatory with new-information/focused NP subjects in Cimbrian: "it is necessary to define a Ground [context] of already known information against which the new subject is set" (414).

There are two observations that render both accounts untenable. First, $d a$ also occurs with given subjects, as in (51b). This observation speaks against the account of Grewendorf \& Poletto (2015). Second, $d a$ is optional in certain contexts. Subject questions with simple $w h$-words, as illustrated in (56), are grammatical both with and without $d a$, as are sentences with negative subjects. This is unexpected in the formal account of Bidese \& Tomaselli (2018).

(56) a. Ber riüft=ta o?

who calls $=D A$ up

'Who is calling?'

b. Ber riüft o?

who calls up 


\section{Roland Hinterhölzl}

\subsection{The Alternative Account}

I propose that clitics and $d a$ have the role of anchoring the utterance in the context (see Cognola \& Hinterhölzl 2016). This implies that $d a$ is not an element that lacks referential content (as is assumed in the literature for German(ic) expletives; see Biberauer \& Van der Wal 2014, Biberauer 2016 for a similar view) but an element that makes salient the reference to the utterance situation, while clitics make salient a previous situation by referring to an individual in a discourse-given situation.

The alternative proposal has to capture the mixed licensing conditions for $d a$. There is a semantic side of the licensing of $d a$ : $d a$ is obligatory with indefinite and focused subjects. In this case the subject is not a referential DP, hence the sentence must be anchored in the context with respect to a given situation. Thus the focused definite subject in (53a) must be taken to have a strong (but not referential) reading. This makes sense since a DP that constitutes new information cannot already be given in the context but may be directly identifiable in it. The matter is less clear in cases of contrastive focus. In our account, however, we are forced to say that a definite DP that constitutes a contrastive focus (a particular choice out of a given set of alternatives) can only have a strong but nonreferential interpretation.

There is also a syntactic side of the licensing of $d a$ : $d a$ (or a clitic) is necessary if the subject has to stay in a lower position because another element has been moved into the $\mathrm{C}$ domain. The latter effect can be shown to be the result of a new interpretation of the properties of V2 (cf. Poletto 2002, Benincà 2006, Wolfe 2015). As is proposed in Hinterhölzl 2017, V2 creates a bottleneck effect in FinP (cf. Haegeman 1996, Roberts 2004), implying that only one constituent may be moved with the verb into the $\mathrm{C}$ domain. Movement of the wh-element into the $\mathrm{C}$ domain is obligatory in Cimbrian questions and thus blocks movement of the subject into Spec,FinP. This, I argue, blocks anchoring of the utterance in the context by a referential subject and requires the activation of an alternative anchor, either $d a$ or a subject clitic, as in (51a,b) above.

To make sense of this restriction, I suggest that the assignment of a value to a referential DP as well as the assignment of a concrete value to the reference situation is not achieved via an assignment function in semantics and thus possible in any position in the clause but is instead tied to a specific syntactic position. I propose that it is in FinP that the values of the reference situation and the values of discourse antecedents of referential DPs are assigned. This analysis is supported by the following observations. Referential subjects can always anchor the predicate if they move into a prefinite position, that is, into Spec,FinP:

(57) a. Dar Mario hat gekhoaft in liber.

the Mario has bought the book

'Mario bought the book.'

b. *Dar $\mathrm{Mario}_{j}$ hat=ta/hat $=\mathrm{ar}_{j}$ gekhoaft in liber.

the Mario has $=D A /$ has $=$ he bought the book 
Nonreferential subjects can anchor the utterance by moving into or rather through Spec,FinP if they have a strong interpretation:

(58) a. Belz khinn hatt bokhennt soin tatta? which child has met his father 'Which child met his father?'

b. *Belz khinn hatt=ta bokhennt soin tatta? which child has $=D A$ met his father

Nonreferential subjects with a simple quantifier can anchor the utterance if the context requires a strong interpretation, as in (60), but require the presence of $d a$ if they have a weak interpretation, as in (59).

(59) a. Ber riüft=ta o?

who calls $=D A$ up

'Who is calling?'

b. Ber riüft o?

who calls up

(60) a. Ber riüft=ta o?

who calls $=D A$ up

'Which of us is going to make the phone call?'

b. Ber riüft o?

who calls up

In (59) are given the judgments of native speakers (on a five-point Likert scale) for a sentence with and without $d a$ in a context in which the subjects are watching TV and hear the telephone ring and ask who is calling in that moment. In (60), on the other hand, are native speakers' judgments in the situation where the subject and his friends have to book a room for the weekend and it is not yet decided who is supposed to call the hotel and one of them asks who (of them) will make the phone call.

In the first context, the $w h$-subject has a weak reading, making necessary the alternative anchor $d a$. In the second context, the $w h$-subject necessarily has a strong, referential reading, excluding $d a$. These facts support the analysis that a $w h$-subject moving through Spec,FinP on its way to Spec,ForceP can anchor the utterance in the context if it has a strong, referential reading. If it has a weak reading, an alternative anchor is needed.

Let us summarize where we stand at this point. In Fin $^{0}$, the lowest head in the $\mathrm{C}$ domain, the concrete values for a reference situation and for the individual argument of a referential subject DP are assigned or become accessible (possibly by entering into a local Agree relation with a higher head). Movement of a referential or strong subject anchors the utterance in the context. If the subject cannot anchor the clause for semantic reasons (because it is indefinite and nonspecific) or for syntactic reasons (because its movement into the $\mathrm{C}$ domain is blocked by the obligatory movement into 


\section{Roland Hinterhölzl}

the C domain of another constituent), an alternative anchor is needed. This is regularly the case in nonsubject questions, as is illustrated in $(51 \mathrm{a}, \mathrm{b})$ above.

These data, however, also pose the question how a potentially referential subject DP can be licensed in a postverbal position, which is assumed to be a vP-internal position. I propose that the D layer of a definite DP, or strong DP in general, licenses a correlate DP in its specifier:

(61) $\left[\mathrm{DP}[\mathrm{DP} \mathrm{da} / \mathrm{sBJ}]\left[\mathrm{D}_{0}[\mathrm{NP} \mathrm{N}]\right]\right]$

Alternatively, one could assume that clitics are base generated in a higher position in the $\mathrm{T}$ domain and enter into an Agree relation with the vP-internal DP argument. Since the differences between these two accounts are immaterial for our purposes, I will assume the first version without any further argument.

If the DP has a strong interpretation, the correlate DP in its specifier is realized as the clitic element $d a$ and is subextracted, undergoing XP movement to Spec,TP and subsequent head movement to FinP, where it is assigned a concrete value for its situation argument. This value is then transferred via Spec-head agreement to the D head of the DP in the vP. In a similar vein, if the DP has a referential interpretation, its correlate DP is realized as a subject clitic that is likewise subextracted and moved via Spec,TP to Fin ${ }^{0}$ to be assigned a concrete value for the individual argument, which is then transferred (via Spec-head agreement) to the D head of the DP in the vP. If a strong or referential DP is moved into Spec,FinP, $d a$ or the clitic remain silent.

In the case of an indefinite, nonspecific subject, I propose, following Kallulli (2008), that a locative adverbial $d a$ is inserted as the subject of a small clause headed by the indefinite DP. In the present account, clitics are the expression of an Agree relation with a higher head that serves to license nominal expressions in a lower domain. In this sense, subject and object clitics play a similar role as scrambling does in German: in a language that does not allow for scrambling, like Cimbrian, they bring a strong or referential DP into a local relation with the licensing head in the clause.

Questions arise in this respect for a language like English. In the present approach we have to assume that referential and strong DPs in English undergo scrambling as well but that the copy that is spelled out is the lower copy. I will have to leave this issue and alternative approaches, like overt DP movement plus $\mathrm{vP}$ intraposition, for further research.

\section{Summary}

In this article, I have argued that the distribution of DP subjects is decisively determined by their interpretational properties. In particular, I have shown that we can make the distinction between attributive and referential readings of DPs precise if we assume that nominal expressions introduce an individual argument and a situation argument that can vary in their givenness status.

The syntactic distribution of nominal expressions is then determined by the properties of the $\mathrm{D}$ element. A weak determiner imposes no presuppositional 
restrictions on the interpretation of the nominal expression, which is thus interpreted in its base position (in the $\mathrm{v}$ domain), its situation argument being identified with the situation argument of the verb. This corresponds to an attributive use of the nominal expression with a new situation argument.

A strong determiner imposes diverse presuppositions on the interpretation of its nominal complement. A nonanaphoric strong determiner presupposes that the situation argument of the nominal is given in the context. This type of strong DP is interpreted in the $\mathrm{T}$ domain, since the Tense head denotes the so-called reference situation.

An anaphoric strong determiner presupposes that the value of its individual argument, too, is given in the context. This type of strong DP is interpreted in the C domain, where the values of discourse referents become accessible. Empirical evidence for this assumption was provided by an analysis of the distribution of subjects in Cimbrian.

The Cimbrian data make a strong case for the proposal advanced in Hinterhölzl 2019 that the semantic interpretation of DPs does not involve assignment functions in semantics but is syntactically determined in that there is a specific head in the $\mathrm{C}$ domain in which the values of discourse antecedents are accessible. Referential DPs are interpreted by entering into a local relation with this head, resulting in the assignment of a concrete referential value to the DP. This syntactic dependency is made visible via syntactic movement of the entire referential DP into the relevant domain (scrambling) or of a subpart of it to the licensing head in the $\mathrm{C}$ domain (clitic movement).

\section{References}

Austin, J. L. 1961. Truth. In Philosophical papers, ed. J. O. Urmson \& G. J. Warnock, 117 133. Oxford: Oxford University Press.

Barwise, J. \& J. Perry. 1983. Situations and attitudes. Cambridge, MA: MIT Press.

Benincà, P. 1988. Costruzioni con ordini marcati degli elementi [Constructions with marked orders of elements]. In Grande grammatica italiana di consultazione, ed. L. Renzi, G. Salvi \& A. Cardinaletti, 115-195. Bologna, Italy: Il Mulino.

Benincà, P. 2006. A detailed map of the left periphery of Medieval Romance. In Crosslinguistic research in syntax and semantics, ed. R. Zanuttini, H. Campos, E. Herburger \& P. Portner, 53-86. Washington, DC: Georgetown University Press.

Biberauer, T. 2016. There is a lot going on here: (Earlier) English (and other) expletive syntax revisited. Paper presented at diachronic-syntax workshop held in Venice, Italy, October.

Biberauer, T. \& J. van der Wal. 2014. Expletives beyond English. Ms., Cambridge University, Cambridge.

Bidese, E., A. Padovan \& A. Tomaselli. 2012. A binary system of complementizers in Cimbrian relative clauses. Working Papers in Scandinavian Syntax 90:1-20.

Bidese, E. \& A. Tomaselli. 2005. Formen der "Herausstellung" und Verlust der V2-Restriktion in der Geschichte der zimbrischen Sprache [Forms of "extraposition" and loss of the V2 restriction in the history of the Cimbrian language]. In Das Zimbrische zwischen Germanisch und Romanisch, ed. E. Bidese, J. R. Dow \& T. Stolz, 71-92. Bochum, Germany: Brockmeyer.

Bidese, E. \& A. Tomaselli. 2018. Developing pro-drop: The case of Cimbrian. In Null subjects in generative grammar: A synchronic and diachronic perspective, ed. F. Cognola \& J. Casalicchio. Oxford: Oxford University Press. 


\section{Roland Hinterhölzl}

Bošković, Z. 1997. The syntax of nonfinite complementation: An economy approach. Cambridge, MA: MIT Press.

Brentano, F. 1874. Psychology from an empirical point of view. London: Routledge.

Cardinaletti, A. \& M. Starke. 1999. The typology of structural deficiency: A case study of three classes of pronouns. In Clitics in the languages of Europe: Empirical approaches to language typology, ed. H. van Riemsdijk, 145-233. Berlin: Mouton de Gruyter.

Chierchia, G. 1995. Individual level predicates as inherent generics. In The generic book, ed. G. N. Carlson \& F. I. Pelletier, 176-223. Chicago: Chicago University Press.

Chomsky, N. 1981. Lectures on government and binding. Dordrecht, the Netherlands: Foris.

Chomsky, N. 1995. The Minimalist Program. Cambridge, MA: MIT Press.

Chomsky, N. 2000. New horizons in the study of language and mind. Cambridge: Cambridge University Press.

Chomsky, N. 2001. Derivation by phase. In Ken Hale: A life in language, ed. M. Kenstowicz, 1-52. Cambridge, MA: MIT Press.

Cognola, F. \& R. Hinterhölzl. 2016. On the interaction between V2, subjects and wh-movement in a comparative perspective. Paper presented at the 22nd Germanic Linguistics Annual Conference, University of Iceland, Reykjavík, May 21.

Cognola, F. \& R. Hinterhölzl. To appear. Syntactic and semantic restrictions in the licensing of subjects in Cimbrian main clauses. Linguistische Berichte.

Davidson, D. 1967. The logical form of action sentences. In Essays in honour of Carl G. Hempel, ed. N. Resher, 216-234. Dordrecht, the Netherlands: Reidel.

Déprez, V. 2000. Parallel (a)symmetries and the structure of negative expressions. Natural Language and Linguistic Theory 18:253-342.

Diesing, M. 1992. Indefinites. Cambridge, MA: MIT Press.

Donellan, K. 1966. Reference and definite descriptions. Philosophical Review 75:281304.

Ebert, K. 1971. Zwei Formen des bestimmten Artikels [Two forms of the definite article]. In Probleme und Fortschritte der Transformationsgrammatik, ed. D. Wunderlich, 159-174. Munich: Hueber.

É. Kiss, K. 1996. Two subject positions in English. Linguistic Review 13:119-142.

Elbourne, P. 2013. Definite descriptions. Oxford: Oxford University Press.

Felser, C. \& L. Rupp. 2001. Expletives as arguments: Germanic existential sentences revisited. Linguistische Berichte 187:289-324.

Fodor, J. 1970. The linguistic description of opaque contents. Doctoral thesis, Massachusetts Institute of Technology, Cambridge.

Giorgi, A. \& F. Pianesi. 1997. Tense and aspect: From semantics to morphosyntax. New York: Oxford University Press.

Grewendorf, G. \& C. Poletto. 2015. Relative clauses in Cimbrian. In Structure, strategies and beyond: Studies in honor of Adriana Belletti, ed. E. Di Domenico, 393-416. Amsterdam: John Benjamins.

Hacquard, V. 2010. On the event-relativity of modal auxiliaries. Natural Language Semantics 18:79-114.

Haegeman, L. 1996. Verb second, the split CP, and null subjects in early Dutch finite clauses. Geneva Generative Papers 4:135-175.

Hartmann, J. 2008. Expletives in existentials: English there and German $d a$. Doctoral thesis, Tilburg University, Tilburg, the Netherlands.

Hazout, I. 2004. The syntax of existential constructions. Linguistic Inquiry 35:393-430.

Heinrichs, H. 1954. Studien zum bestimmten Artikel in den germanischen Sprachen [Studies on the definite article in Germanic languages]. Giessen, Germany: Wilhelm Schmitz.

Herburger, E. 1997. Focus and weak noun phrases. Natural Language Semantics 5:53-78.

Higginbotham, J. 1987. Indefiniteness and predication. In The representation of (in) definiteness, ed. E. Reuland \& A. ter Meulen, 43-70. Cambridge, MA: MIT Press. 
Higginbotham, J. \& G. Ramchand. 1997. The stage-level/individual-level distinction and the mapping hypothesis. Oxford University Working Papers in Linguistics, Philology and Phonetics 2:53-83.

Hinterhölzl, R. 2017. Decomposing V2. Stellenbosch Papers in Linguistics Plus 48:205-217.

Hinterhölzl, R. 2019. The role of topics in licensing anaphoric relations in VP-ellipsis. In The architecture of topics, ed. V. Molnar \& S. Winkler, 67-93. Berlin: Mouton de Gruyter.

Hinterwimmer, S. \& C. Endriss. 2006. Topic interpretation in determiner and adverbial quantification. In Proceedings of the 36th annual meeting of the North East Linguistic Society, ed. C. Davies, A. R. Deal \& Y. Zabbal, 241-252. Amherst, MA: Graduate Linguistic Student Association, University of Massachusetts.

Hoekstra, T. \& R. Mulder. 1990. Unergatives as copular verbs: Locational and existential predication. Linguistic Review 7:1-79.

Holmberg, A. \& C. Platzack. 1995. The role of inflection in Scandinavian syntax. Oxford: Oxford University Press.

Jenkins, L. 1975. The English existential. Tübingen, Germany: Niemeyer.

Kallulli, D. 2008. There is secondary predication in there-existentials. In Proceedings of the 26th West Coast Conference on Formal Linguistics, ed. C. B. Chang \& J. H. Hannah, 279287. Somerville, MA: Cascadilla Proceedings Project.

Keshet, E. 2008. Good intensions: Paving two roads to a theory of the de relde dicto distinction. Doctoral thesis, Massachusetts Institute of Technology, Cambridge.

Keshet, E. \& F. Schwarz. 2014. De re/de dicto. Ms., University of Michigan, Ann Arbor \& University of Pennsylvania, Philadelphia.

Kolmer, A. 2005. L'espletivo $d a$ come espletivo della posizione del soggetto enclitico pronominale nel Cimbro di Luserna [The expletive da as an expletive of the pronominal enclitic subject position in the Cimbrian of Luserna]. In L'influsso dell'italiano sulla grammatica delle lingue minoritarie: Problemi di morfologia e sintassi, ed. W. Breu, 55-92. Rende, Italy: Centro Editoriale e Librario, Università della Calabria.

Kratzer, A. 1989. Stage-level and individual-level predicates. Ms., University of Massachusetts, Amherst.

Kratzer, A. 1995. Stage-level and individual-level predicates. In The generic book, ed. G. N. Carlson \& F. I. Pelletier, 125-175. Chicago: University of Chicago Press.

Kratzer, A. 2004. Covert quantifier restrictions in natural languages. Ms., University of Massachusetts, Amherst.

Kratzer, A. 2006. Situations in natural language semantics. Ms., University of Massachusetts, Amherst.

Kratzer, A. 2007. On the quantification over times in natural language. Natural Language Semantics 13:317-357.

Kuroda, Y. 1972. The categorical and the thetic judgment. Foundations of Language 9:153-185.

Ladusaw, W. 1994. Thetic and categorical, stage and individual, weak and strong. In Proceedings from Semantics and Linguistics Theory 4, ed. M. Harvey \& L. Santelmann, 220-229. Ithaca, NY: Cornell University.

May, R. 1977. The grammar of quantification. Doctoral thesis, Massachusetts Institute of Technology, Cambridge.

Milsark, G. 1974. Existential sentences in English. Doctoral dissertation, Massachusetts Institute of Technology, Cambridge.

Moro, A. 1997. The raising of predicates: Predicative noun phrases and the theory of clause structure. Cambridge: Cambridge University Press.

Percus, O. 2000. Constraints on some other variables in syntax. Natural Language Semantics 8:173-229.

Poletto, C. 2002. The left-periphery of V2-Rhaetoromance dialects: A new view on V2 and V3. In Syntactic microvariation, ed. S. Barbiers, L. Cornips \& S. van der Kleij, 214-242. Amsterdam: Meertens Institute, Royal Netherlands Academy of Sciences. http://www.meerte ns.knaw.nl/books/synmic/. 


\section{Roland Hinterhölzl}

Ramchand, G. 1997. Aspect and predication: The semantics of argument structure. Oxford: Oxford University Press.

Reichenbach, H. 1947. Elements of symbolic logic. New York: Macmillan.

Rizzi, L. 1997. The fine structure of the left periphery. In Elements of grammar, ed. L. Haegeman, 281-337. Dordrecht, the Netherlands: Kluwer.

Roberts, I. G. 2004. The C-system in Brythonic Celtic languages, V2, and the EPP. In The structure of CP and IP, ed. L. Rizzi, 297-328. Oxford: Oxford University Press.

Russell, B. 1905. On denoting. Mind 14:479-493.

Sabel, J. 2000. Expletives as features. In Proceedings of the 19th West Coast Conference on Formal Linguistics, ed. R. Billerey \& B. D. Lillehaugen, 411-424. Somerville, MA: Cascadilla.

Safir, K. 1982. Syntactic chains and the definiteness effect. Doctoral thesis, Massachusetts Institute of Technology, Cambridge.

Scheutz, H. 1988. Determinantien und Definitheitsarten im Bairischen und Standarddeutschen [Determiners and definiteness types in Bavarian and Standard German]. In Festschrift für Ingo Reiffenstein, ed. P. K. Stein, 231-253. Göppingen, Germany: Kümmerle.

Schwager, M. 2007. (Non-)functional concepts: Definite articles in Bavarian. Talk presented at the eighth Szkarska Poreba Workshop, Szrenica, Poland, February 23-27.

Schwarz, F. 2009. Two types of definites in natural language. Doctoral thesis, University of Massachusetts, Amherst.

Schwarz, F. 2012. Situation pronouns in determiner phrases. Natural Language Semantics 20:431-475.

Stowell, T. 1978. What was there before there was there? In Proceedings of the 14th regional meeting of the Chicago Linguistic Society, ed. D. Farkas, 457-471. Chicago: University of Chicago.

Strawson, P. 1950. On referring. Mind 59:320-344.

Vendler, Z. 1957. Verbs and times. Philosophical Review 66:143-160.

Williams, E. 1994. Thematic structure in syntax. Cambridge, MA: MIT Press.

Wolfe, S. 2015. Microvariation in Medieval Romance syntax: A comparative study. Doctoral thesis, Cambridge University, Cambridge.

Roland Hinterhölzl

Dipartimento di Studi Linguistici e Culturali Comparati

Università Ca' Foscari

Ca’Bembo, Dorsoduro 1075

30123 Venezia

Italy

rolandh@unive.it 